\title{
Analisis Kestabilan Bendung Untuk Pemenuhan Kebutuhan Air (Studi Kasus Kota Bima)
}

\author{
Muhammad Fathin Firaz ${ }^{1 *}$, Alpiana ${ }^{1}$, Isfanari ${ }^{2}$, Diah Rahmawati ${ }^{1}$, Ariyanto ${ }^{1}$ \\ ${ }^{1}$ Program Studi S1 Teknik Pertambangan, Fakultas Teknik, Universitas Muhammadiyah Mataram, Mataram, \\ Indonesia \\ ${ }^{2}$ Program Studi Teknik Sipil, Fakultas Teknik, Universitas Muhammadiyah Mataram, Mataram, Indonesia
}

* Corresponding author : ruztdaloccozz@gmail.com

Received: Dec 11, 2021; Accepted: Dec 27, 2021.

DOI: https://doi.org/10.31764/jpl.v2i2.7390

\begin{abstract}
Abstrak. Saat ini sering sekali ditemukan bendung-bendung yang rusak atau tidak stabil sehingga akan mempengaruhi produksi para petani. Sebuah bangunan bendung harus memenuhi persyaratan stabilitas yang menjadi salah satu syarat penting guna menjamin umur bendung dan kemampuannya untuk menaikkan muka air yang mengalir menuju lahan pertanian. Rencana pembangunan Bendung Dodu di Sungai Dodu Kecamatan Rasanae Timur Kota Bima harus dilakukan perhitungan stabilitas. Hal ini bertujuan untuk menjamin bendung memiliki stabilitas yang aman. Dengan bendung yang aman, maka masyarakat di Kecamatan Rasanae Barat dapat tercukupi kebutuhan air dengan umur bendung yang lebih lama. Manfaat dari penelitian yang dilakukan adalah sebagai bahan referensi bagi pihak yang akan melakukan penelitian yang sama terkait stabilitas suatu bendung. Metode pengumpulan data dilakukan dengan data primer dan sekunder. Data tersebut kemudian dianalisis dengan perhitungan momen, daya dukung tanah, dan faktor keamanan. Berdasarkan dari hasil perhitungan kestabilan bendung Dodu diperoleh bahwa dimensi mercu bendung Dodu yang diusulkan memiliki tinggi 4,5 meter, lebar $6 \mathrm{~m}$ dan panjang 20 meter. Dengan geometri Bendung Dodu tersebut hasil perhitungan Faktor Keamanan terhadap geser yaitu 5,85 dan lebih besar dari 1,5 sehingga aman atau stabil dan untuk keamanan terhadap guling yaitu sebesar 2,58 yang lebih besar dari 1,5 sehingga aman (stabil).
\end{abstract}

Kata Kunci: stabilitas, factor Keamanan, bendungan.

Abstract. Currently, damaged or unstable dams are often found, which will affect the production of farmers. A weir structure must meet the stability requirements, which are important requirements to ensure the life of the weir and its ability to raise the water level that flows into agricultural land. The plan for the construction of the Dodu Weir on the Dodu River., East Rasanae District, Bima City, must be calculated for stability. With a safe weir, the people in West Rasanae District can meet their water needs with a longer weir life. The benefit of the research conducted is as reference material for those who will conduct the same research related to the stability of a weir. The method of data collection was carried out with primary and secondary data. The data is then analyzed by calculating the moment, soil bearing capacity, and safety factor. Based on the calculation of the stability of the Dodu dam, it was found that the dimensions of the proposed Dodu weir crest have a height of 4.5 meters, a width of 6 meters, and a length of 20 meters. With the geometry of the Dodu weir, the calculation result of the safety factor against shear is 5.85 and greater than 1.5 , so it is safe or stable, and for safety against rolling, it is 2.58 , which is greater than 1.5 , so it is safe (stable).

Keywords: stability, safety factor, dam.

\section{Pendahuluan}

Air merupakan salah satu elemen yang sangat dibutuhkan dalam kehidupan mahluk hidup baik hewan, tumbuhan maupun manusia. Manfaat air yang dapat kita rasakan salah satunya adalah untuk irigasi (Firnanda, et al., 2011). Namun karena curah hujan yang berbeda-beda setiap bulannya mengakibatkan kebutuhan air bagi lahan pertanian tidaklah cukup. Untuk memenuhi kebutuhan air untuk irigasi, diperlukan sebuah bangunan air yang mampu mengaliri lahan pertanian sepanjang tahunnya (Prasasti, et al., 2013). 
Bendung merupakan bangunan melintang sungai yang bermanfaat untuk meninggikan muka air sungai untuk keperluan irigasi dan keperluan lainnya (Prastumi \& Pratama, 2011). Dalam pembangunannya sering sekali ditemukan bendung-bendung yang rusak atau tidak stabil sehingga akan mempengaruhi produksi para petani. Sebuah bangunan bendung harus memenuhi persyaratan stabilitas yang menjadi salah satu syarat penting guna menjamin umur bendung dan kemampuannya untuk menaikkan muka air yang mengalir menuju lahan pertanian.

Rencana pembangunan Bendung Dodu berlokasi di Sungai Dodu Kecamatan Rasanae Timur Kota Bima juga harus dilakukan perhitungan stabilitas. Hal ini dikarenakan lokasi Kecamatan Rasanae Timur secara geografis memiliki curah hujan yang lebih kecil, sehingga kebutuhan air belum tercukupi. Untuk mengatasi permasalahan tersebut sangat perlu dilakukan pembangunan bendung. Namun sebelum dilakukan pembangunan, analisis terhadap stabilitas perlu dilakukan. Hal ini bertujuan untuk menjamin bendung memiliki stabilitas yang aman. Bendung yang aman akan mempengaruhi umur bendung yang lebih lama, sehingga kebutuhan air bagi masyarakat dapat tercukupi dalam waktu yang lebih lama (Mangroe, et al., 2013), begitu juga dengan pemenuhan air bagi masyarakat di Kecamatan Rasanae Barat. Manfaat dari penelitian yang dilakukan adalah sebagai bahan referensi bagi pihak yang akan melakukan penelitian yang sama terkait stabilitas suatu bendung.

\section{Metode Penelitian}

Metode penelitian yang digunakan dalam penelitian ini adalah dengan mengambil data primer dan data sekunder. Data primer yang digunakan yaitu data sampel tanah yang dilakukan pengujian di laboratorium. Sedangkan data sekunder yang digunakan dalam penelitian ini adalah data curah hujan, dan data rancang bangun bendung. Metode penelitian yang digunakan dalam penelitian ini adalah dengan melakukan pengambilan data dengan metode yang tepat. Menurut Firnanda dkk (2011) dan Asl dkk (2015), data-data yang digunakan meliputi gaya vertikal, gaya horizontal, dan momen gaya. Dalam penelitian ini telah dilakukan:

a) Pengambilan data untuk perhitungan gaya vertikal, gaya horizontal, dan momen.

Data-data yang digunakan untuk melakukan perhitungan yaitu desain atau rancangan bendung (Sukirman, 2014). Dari rancangan bendung yang dilakukan maka akan dapat dilakukan perhitungan berapa gaya vertikal, gaya horizontal dan momen pada bendung. Persamaan dalam perhitungan yaitu:

Persamaan Gaya Vertikal dihitung menggunakan Pers. (1), dimana $V f$ menyatakan Gaya vertikal pada tubuh bendung dengan satuan $\mathrm{kN}$ (kilonewton). $W_{1}, W_{2}$, dan $W_{3}$ berturut-turut menyatakan berat tubuh bendung pada masing-masing bagian dengan satuan $\mathrm{kN}$ (kilonewton).

$$
V f=W_{1}+W_{2}+W_{3}
$$

Persamaan gaya angkat (U) dihitung menggunakan Pers. (2)

$$
U=\frac{\text { lebar mercu } \times \text { panjang mercu } \times \text { berat air }}{2}
$$

Persamaan gaya Horizontal (Hf) dihitung menggunakan Pers. (3)

$$
H f=\frac{\text { panjang mercu } \times \text { tinggi air } \times \text { densitas air }}{2}
$$

Reaksi Vertikal $\left(R_{y}\right)$ dihitung menggunakan Pers. (4)

$$
R_{y}=W_{1}+W_{2}+W_{3}-U=V f-U
$$

Perhitungan Momen

$$
\left.R_{m}=\sum \text { (titik seimbang } w \times w\right)
$$

b) Melakukan pengambilan data untuk mengetahui daya dukung tanah

Untuk mengetahui daya dukung tanah dilakukan pengambilan sampel tanah dan dilakukan uji laboratorium untuk mengetahui sifat fisik dan mekanik dari tanah.besaran nilai daya dukung tanah 
didapatkan dari perhitungan terhadap daya dukung yang menggunakan sudut geser dalam perhitungannya (Sofyan \& Frizaldi, 2017). Perhitungan daya dukung dalam penelitian ini menggunakan material pasir lanauan yang merupakan material paling atas pada litologi dasar sungai. Berikut ini adalah perhitungan daya dukung tanah sebagai berikut:

$$
\begin{aligned}
& \text { Daya dukung tanah }(q)=\text { densitas jenuh } \times \text { kedalaman pondasi } \\
& \text { Daya dukung ultimate }\left(q_{u l t}\right)=1,3 \times C \cdot N_{c}+q \cdot N_{q}+0,4 \cdot \gamma^{\prime} \cdot B^{\prime} \cdot N_{\gamma}
\end{aligned}
$$

c) Pengambilan data untuk perhitungan Faktor Keamanan

Dalam melakukan perhitungan Faktor Keamanan yang merupakan perhitungan stabilitas sebuah bangunan bendung untuk dikatakan aman atau stabil (Sabihi, et al., 2011). Data-data yang digunakan dalam perhitungan merupakan data-data gabungan dari perhitungan sebelumnya pada Pers. (1) hingga Pers. (6).

Pada penelitian ini juga menggunakan data curah hujan daerah setempat. Data hujan yang digunakan dalam penelitian ini terlebih dahulu dilakukan uji konsistensi dengan metode statistik. Pengujian ini diperlukan untuk menghindari data yang tidak valid.

\section{Hasil dan Pembahasan}

Perhitungan analisis kestabilan bendung diperlukan dalam suatu perencanaan suatu bendung. Stabilitas konstruksi akan diperhitungkan terhadap gaya geser, gaya guling, daya dukung tanah, rembesan, penurunan dan retakan. Kondisi yang ditinjau adalah kondisi saat muka air banjir, hal ini dikarenakan pada saat itulah bendung akan mengalami tekanan yang paling besar.

Dalam penelitian yang dilakukan, geometri bendung yang digunakan dalam perhitungan ditunjukkan oleh Gambar 1 berikut:

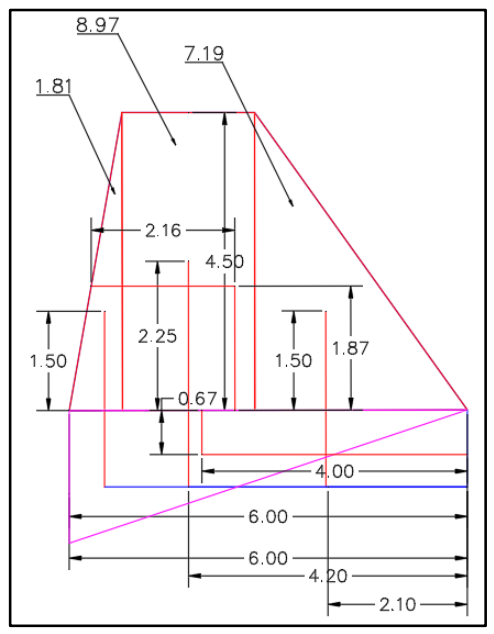

Gambar 1. Geometri Tubuh bendung Sebagai dasar Perhitungan Stabilitas Bendung

Dengan geometri tubuh bendung di atas sehingga perhitungan-perhitungan untuk analisis kestabilan bendung dapat dilakukan.

a) Gaya Vertikal

Perhitungan gaya-gaya vertikal yang bekerja pada tubuh bendung bertujuan untuk mengetahui berat bendung secara vertikal. Perhitungan gaya vertikal menggunakan Pers. (1) sehingga diperoleh besarnya gaya vertikal untuk rencana bendung Dodu yaitu sebesar $8.623,87 \mathrm{kN}$ dengan nilai $W_{1}, W_{2}$, dan $W_{3}$ berturut-turut $868,63 \mathrm{kN}, 4.304,74 \mathrm{kN}$ dan $3.450,51 \mathrm{kN}$.

b) Gaya Angkat

Perhitungan gaya angkat utuk rencana bendung Dodu menggunakan Pers. (2), diperoleh nilai sebesar $2.700 \mathrm{kN}$ dengan rincian perhitungan sebagai berikut:

$$
\text { Berat air }\left(W_{a}\right)=\text { densitas air } \times \text { ting gi air }=10 \times 4,5=45 \mathrm{kN} / \mathrm{m}^{2}
$$




$$
U=\frac{\text { lebar mercu } \times \text { panjang mercu } \times \text { berat air }}{2}=\frac{20 \times 6 \times 45}{2}=2700 \mathrm{kN}
$$

c) Gaya Horizontal

Perhitungan gaya horizontal utuk rencana bendung Dodu menggunakan Pers. (3), diperoleh nilai gaya horizontal sebesar $135 \mathrm{kN}$. Rincian perhitungan gaya horizontal sebagai berikut:

$$
H f=\frac{\text { panjang mercu } \times \text { tinggi air } \times \text { densitas air }}{2}=\frac{6 \times 4,5 \times 10}{2}=135 \mathrm{kN}
$$

d) Reaksi

Dalam perhitungan reaksi maka reaksi dibagi menjadi 2 (dua) yaitu:

- Reaksi Vertikal

Reaksi vertikal yang terjadi pada tubuh bendung adalah gaya berat yang bekerja pada bendung dikurangi dengan gaya angkat pada bendung. Untuk perhitungan menggunakan pers. (4) sehingga siperoleh nilai Ry sebesar 5.923,87 kN.

- Reaksi Horizontal $(R x)$ merupakan reaksi yang timbul akibat adanya gaya air yang bekerja pada bendung sehingga nilainya sama dengan nilai $H f$ yaitu sebesar $135 \mathrm{kN}$.

e) Momen

Dalam perhitungan momen bendung Dodu maka perhitungan momen yang dihitung adalah perhitungan momen di toe sebelah kanan bendung dengan perhitungan menggunakan

Pers. (5) sebagai berikut:

$$
\begin{aligned}
R_{m} & =\sum(\text { titik seimbang } w \times w) \\
& =(5,47 \times 868,3)+(4,20 \times 4.304,74)+(2,13 \times 3.450,51)=30.194,65 \mathrm{kNm}
\end{aligned}
$$

Selain momen di toe, dalam perhitungan momen juga dilakukan perhitungan di momen sisi kiri dan kanan kaki bendung dengan tujuan mencegah terjadinya guling dengan perhitungan sebagai berikut:

$$
\begin{aligned}
O_{m} & =(\text { titik berat air } \times \text { berat air })+(\text { titik berat } U \times U) \\
& =\left(\frac{1}{3} \times 4,5 \times 607,50\right)+(4 \times 2.699)=11.709,09 \mathrm{kNm}
\end{aligned}
$$

Jadi besarnya momen di toe adalah sebesar $30.194,65 \mathrm{kNm}$ dan overturning momen sebesar $11.709,09 \mathrm{kNm}$.

f) Daya Dukung Tanah

Besaran nilai daya dukung tanah didapatkan dari perhitungan terhadap daya dukung yang menggunakan sudut geser dalam perhitungannya. Perhitungan daya dukung ini menggunakan material pasir lanauan (material paling atas pada litologi dasar sungai. Berikut adalah perhitungan daya dukung tanah dengan menggunakan Pers. (6) dan Pers. (7) sebagai berikut:

$$
\begin{aligned}
& \text { Daya dukung tanah }(q)=\text { densitas jenuh } \times \text { kedalaman pondasi } \\
& =7,95 \times 2=15,90 \mathrm{kN} / \mathrm{m}^{2} \\
& \text { Daya dukung ultimate }\left(q_{u l t}\right)=1,3 \times C \cdot N_{c}+q \cdot N_{q}+0,4 \cdot \gamma^{\prime} \cdot B^{\prime} \cdot N_{\gamma} \\
& =1,3 \times(0,07 \times 23)+(15,90 \times 12)+(0,4 \times 7,95 \times 2 \times 10) \\
& =332,81 \mathrm{kN} / \mathrm{m}^{2}
\end{aligned}
$$

Jadi besarnya daya dukung tanah adalah sebesar $15,90 \mathrm{kN} / \mathrm{m} 2$ dan besarnya daya dukung ultimate sebesar $332,81 \mathrm{kN} / \mathrm{m}^{2}$.

g) Rembesan

Perhitungan terhadap rembesan atau aliran air yang melalui tubuh bendung adalah sebagai berikut.

- $\quad$ Panjang bidang rembesan $(\mathrm{V}+\mathrm{H})=12.095 \mathrm{~m}$

- $\quad$ Angka rembesan lane $(\mathrm{Cl})=2,6$

- $\quad$ Beda tinggi air hulu - hilir $=2 \mathrm{~m}$

- $\quad$ Rembesan saat banjir $(\mathrm{SB})=\mathrm{Cl} \times$ beda tinggi air hulu hilir $=2,6 \times 2=5,2 \mathrm{~m}$ 
Gambar rembesan dengan menggunakan perangkat lunak yaitu sesuai gambar 2 di bawah ini dimana pemodelan total head pada tinggi muka air $4,5 \mathrm{~m}$ :

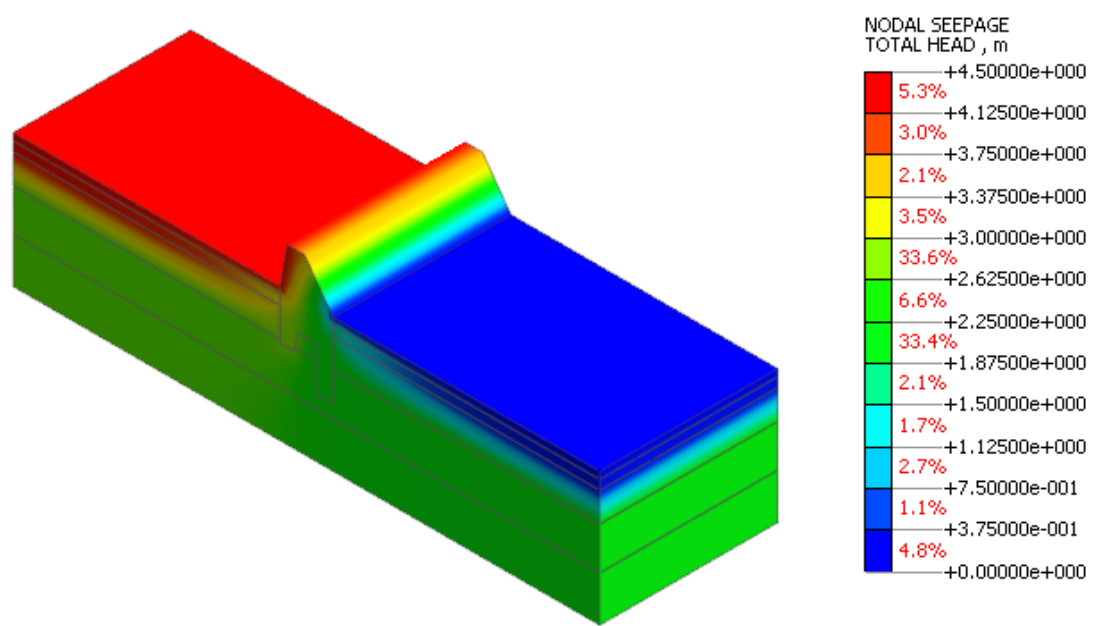

h) Retakan

Gambar 2. Pemodelan rembesan pada bendung

Perhitungan terhadap retakan yang terjadi pada tubuh bendung dilakukan sebagai berikut:

- $\quad$ Titik berat terhadap sumbu $\mathrm{x}(\mathrm{y})=1,87 \mathrm{~m}$

- $\quad$ Titik berat terhadap sumbu y $(\mathrm{x})=2,16 \mathrm{~m}$

- $\quad 1 / 3 \mathrm{~B}=1 / 3 \times 6=2$

- $\quad 2 / 3 \mathrm{~B}=2 / 3 \times 6=4$

- $\quad \alpha=(V f \times y+H f \times x) / V f$

$=(8,623,87 \times 1,87+607,50 \times 2,16) / 8,623,87=2,02 \mathrm{~m}$

i) Faktor Keamanan

Besaran faktor keamanan merupakan representasi dari konstruksi bendung terhadap kondisikondisi yang dapat membuatnya runtuh (gagal). Berikut perhitungan faktor keamanan konstruksi bendung.

- Keamanan terhadap geser $\quad=$ koefisien friction $\times \mathrm{Ry} / \mathrm{Rx}$

$$
\begin{aligned}
& =0,60 \times 5.924,41 / 607,50 \\
& =5,85>1,5(\mathrm{aman})
\end{aligned}
$$

- Keamanan terhadap guling $\quad=\mathrm{RM} / \mathrm{OM}$

$=30.194,65 / 11.709,009$

$=2,58>1,5($ aman $)$

- Daya dukung tanah

$=$ daya dukung ijin $/$ tekanan bendung

$=166,41 / 1.610,13$

$=0,10<1,5$ (tidak aman), terjadi penurunan

- Rembesan

$=\mathrm{SB}<(\mathrm{V}+\mathrm{H})$

$=5,20<12,10($ aman $)$

- Retakan

$=1 / 3 \mathrm{~B}<\alpha<2 / 3 \mathrm{~B}$

$=2<2,02<4$ (aman)

Jadi, besaran Faktor keamanan terhadap geser yaitu 5,85 dan lebih besar dari 1,5 sehingga aman atau stabil dan untuk keamanan terhadap guling yaitu sebesar 2,58 yang lebih besar dari 1,5 sehingga aman (stabil).

\section{Kesimpulan}

Berdasarkan dari hasil perhitungan kestabilan bendung Dodu didapatkan beberapa kesimpulan yaitu dimensi mercu bendung Dodu yang diusulkan memiliki tinggi 4,5 meter, lebar 6 meter dan panjang 20 meter. Dengan geometri Bendung Dodu tersebut hasil perhitungan Faktor Keamanan 
terhadap geser yaitu 5,85 dan lebih besar dari 1,5 sehingga aman atau stabil dan untuk keamanan terhadap guling yaitu sebesar 2,58 yang lebih besar dari 1,5 sehingga aman (stabil).

\section{Referensi}

Asl, M. S., Parvizi, M., Armin, M. \& Berronnes, R. F., 2015. Internal Erosion under Spillway Rested on an Embankment Dam. International Journal of Mining and Geo-Engineering, 49(2), pp. 269-279.

Firnanda, A., Fauzi, M. \& Siswanto, 2011. Analisis Stabilitas Bendung (Studi Kasus: Bendung Tamiang). JomFTEKNIK, 3(2), pp. 1-11.

Mangroe, V. R., Wuisan, E. M., Kawet, L. \& Tangkudung, H., 2013. Perencanaan Bendung untuk Daerah Irigasi Sulu. Jurnal Sipil Statik, 1(7), pp. 533-541.

Prasasti, I., suprapto, M. \& Surjandari, N. S., 2013. Evaluasi Hidrolis Kerusakan dan Konsep Perbaikan Bendung Cileumeuh di Kabupaten Cilacap. Jurnal Teknik Sipil, 1(1), pp. 54-65.

Prastumi, S. H. \& Pratama, F. Y., 2011. Studi Perencanaan Bentuk Bendungan Beton Sederhana yang Paling Efisien. Rekayasa Sipil, 4(2), pp. 1-17.

Sabihi, S., Fauzi, M. \& Siswanto, 2011. Analisis Perencanaan Bendung (Studi Kasus Bendung Botung). JomFTEKNIK, 4(2), pp. 1-17.

Sofyan, Z. \& Frizaldi, 2017. Analisa Desain Bendung di Kawasan Sawah Laweh Tarusan (3273 Ha) Kabupaten Pesisir Selatan Provinsi Sumatera Barat. Jurnal Teknik Sipil ITP, 4(1), pp. 70-78.

Sukirman, 2014. Analisis Rembesan Pada Bendung Tipe urugan Melalui Uji Hidrolik di Laboratorium Hidro FT UNSRI. Jurnal Teknik Sipil dan Lingkungan, 2(2), pp. 238-244. 